ARTIGO ORIGINAL

\title{
Efeito na indução do enraizamento em função da forma e ao tempo de preparo das miniestacas de Toona ciliata e híbridos de Eucalyptus grandis $\mathrm{x}$ Eucalyptus urophylla
}

\author{
Effect on the induction of rooting related to the shape and the time of \\ preparation of the mini-cuttigs of Toona ciliate and Eucalyptus grandis $x$ \\ Eucalyptus urophylla hybrids
}

\author{
Rodolfo Soares de Almeida ${ }^{1}$ (B), Daniel Barbosa de Almeida ${ }^{1}$ (D), Júlio Cézar Tannure Faria ${ }^{1}$ (B), \\ Lucas Amaral de Melo ${ }^{1}$ (D), Eduardo de Castro Stehling ${ }^{2}$ (D), Erika Steinmetz Vilela ${ }^{3}$ (1) \\ ${ }^{1}$ Universidade Federal de Lavras - UFLA, Lavras, MG, Brasil \\ ${ }^{2}$ Fuste Consultoria Florestal, Campo Belo, MG, Brasil \\ ${ }^{3}$ Bela Vista Florestal, Campo Belo, MG, Brasil
}

Como citar: Almeida, R. S., Almeida, D. B., Faria, J. C. T., Melo, L. A., Stehling, E. C., \& Vilela, E. S. (2020). Efeito na indução do enraizamento em função da forma e ao tempo de preparo das miniestacas de Toona ciliata e híbridos de Eucalyptus grandis x Eucalyptus urophylla. Scientia Forestalis, 48(127), e3089.

https://doi.org/10.18671/scifor.v48n127.09

\begin{abstract}
Resumo
A multiplicação clonal de plantas por meio da miniestaquia, aliada ao melhoramento genético de espécies florestais de rápido crescimento, vem sendo utilizada para ganhos de produtividade em florestas plantadas. Dessa forma, o objetivo deste trabalho foi avaliar a relação quanto à forma e ao tempo de preparo das miniestacas de Toona ciliata M. Roemer e híbridos de Eucalyptus grandis Hillx Eucalyptus urophylla S. T. Blake na indução do enraizamento. Foram avaliados, em experimentos separados, três clones de $T$. ciliata e três clones de E. grandis x E. urophylla, combinados com dois tratamentos, forma de preparo das estacas: 1) Redução de 50\% da área foliar e; 2) Sem a redução do limbo foliar. Foram avaliados o tempo gasto com o preparo das miniestacas para cada uma das parcelas e a porcentagem de miniestacas com indução inicial, enraizadas e com raízes $\geq 10 \mathrm{~cm}$, a cada quatro dias a partir do estaqueamento eno $28^{\circ}$ dia avaliou-se a massa seca radicular. O tempo de preparo das miniestacas sem a redução foliar foi menor e possibilitou uma maior eficiência no preparo das miniestacas. Além disto, a condução de miniestacas com folhas inteiras possibilitou uma redução do tempo de enraizamento em dois clones de $T$. ciliata, bem como, um incremento na massa seca das raízes em todos os clones das duas espécies.
\end{abstract}

Palavras-chave: Cedro australiano; Clonagem; Enraizamento adventício; Propagação assexuada.

\begin{abstract}
Clonal multiplication of plants through mini-cutting, coupled with the genetic improvement of fastgrowing forest species, has been used for productivity gains in planted forests. Thus, the objective of this work was to evaluate the relationship between the shape and time of preparation of the mini-cutting of Toona ciliata M. Roemer and hybrids of Eucalyptus grandis Hill x Eucalyptus urophylla S. T. Blake on rooting induction. Three clones of $T$. ciliata and three clones of $E$. grandis $\times E$. urophylla, combined with two treatments, were evaluated in a separate experiment: 1) Reduction of $50 \%$ of the leaf area and; 2) Without the reduction of the leaf blade. The time spent on the preparation of mini-cuttings for each of the plots and the percentage of mini-cuttings with initial induction, rooted and with roots $\geq 10 \mathrm{~cm}$, were evaluated
\end{abstract}

Fonte de financiamento: Nenhuma.

Conflito de interesse: Nada a declarar.

Autor correspondente: rodoxalmeida1991@gmail.com

Recebido: 6 novembro 2018.

Aceito: 30 agosto 2019.

Editor: Paulo Henrique Müller Silva.

(c) Este é um artigo publicado em acesso aberto (Open Access) sob a licença Creative Commons Attribution, que permite uso, distribuição e reprodução By em qualquer meio, sem restrições desde que o trabalho original seja corretamente citado. 
every four days from the planting, and on the 28th day the dry root mass was evaluated. The preparation time of the mini-cuttings without the leaf reduction was smaller and allowed a greater efficiency in the preparation of the mini-cuttings. In addition, the management of mini-cuttings with whole leaves resulted in a reduction of the rooting time in two clones of $T$. ciliata, as well as an increase in the dry mass of the roots in all the clones of the two species.

Keywords: Australian cedar; Cloning; Adventitious rooting; Asexual propagation.

\section{INTRODUÇÃO}

A demanda por produtos florestais vem direcionando a silvicultura a desenvolver e aperfeiçoar técnicas que ampliem sua produtividade econômica e ambiental (Xavier \& Silva, 2010). A silvicultura de produção no Brasil tem se voltado a espécies de rápido crescimento, principalmente as dos gêneros Eucalyptus e Pinus (Pacheco et al., 2015). No entanto, estudos importantes vêm sendo realizados visando à diversificação da produção florestal e a busca por espécies com alto potencial de produção, sendo uma das espécies de destaque nesse cenário, a T. ciliata (Moretti et al., 2011).

O cedro australiano (Toona ciliata M. Roemer) é uma árvore exótica pertence à família Meliaceae, o qual se destaca pelo seu rápido crescimento em diferentes condições de solo e clima, além do seu elevado potencial produtivo e comercial (Nassur et al., 2013). Possui uma madeira de boa qualidade e grande aceitação para a marcenaria e a construção civil, apresentando densidade média de 0,55 $\mathrm{g} \mathrm{cm}^{-3}$ (Lorenzi, 2003; Souza et al., 2010), sendo considerada equivalente em qualidade ao cedro-brasileiro (Cedrelafissilis Vell.) e ao mognobrasileiro (Swieteniamacrophylla King) (Pereira et al., 2015).

Atualmente, a silvicultura do cedro australiano está em franco desenvolvimento no Brasil, tendo destaque nos estados da região Sudeste (Ribeiro et al., 2014). A propagação desta espécie é usualmente via seminal, porém alguns trabalhos já tem apresentado resultados satisfatórios com a propagação vegetativa (Moraes et al., 2014b; Pereira et al., 2015; Souza et al., 2009).

Dentre as diversas técnicas utilizadas para propagação vegetativa de plantas arbóreas, a miniestaquia é mais aplicada pelas empresas florestais brasileiras, especialmente para clonagem de espécies do gênero Eucalyptus (Goulart \& Xavier, 2010), principalmente no que tange à maximização dos índices de enraizamento (Melo et al., 2011; Oliveira et al., 2012).

A redução das folhas pela metade é uma prática comum no preparo das miniestacas. Este procedimento tem por intuito reduzir a perda de água pela transpiração, assim como evitar a intensa interceptação de água pelas folhas, chamado efeito "guarda-chuva", impedindo o molhamento adequado do substrato (Alfenas et al., 2009). Contudo, a propagação vegetativa de miniestacas sem redução foliar pode favorecer o enraizamento, uma vez que é fonte de fotoassimilados e fitohormônios responsáveis pela diferenciação celular meristemática, como a auxina, além de evitar ferimentos nas folhas, que são meios de entrada para patógenos (Alfenas et al., 2009).

Nesse contexto, objetivou-se avaliar o rendimento operacional durante o processo de coleta e preparo das miniestacas, bem como, avaliar os efeitos da redução da área foliar sobre o enraizamento de miniestacas de $T$. ciliatae E. grandisx E. urophylla.

\section{MATERIAL E MÉTODOS}

O estudo foi conduzido no viveiro da empresa Bela Vista Florestal (20 53' 56.6" S, $45^{\circ} 17^{\prime} 29.3^{\prime \prime}$ W), na cidade de Campo Belo - MG. O clima na região é do tipo Cwa (inverno seco e verão chuvoso) segundo a classificação de Köppen, com temperatura média anual de $23,5^{\circ} \mathrm{C}$ (Dantas et al., 2007), e regime pluviométrico anual médio de $1620 \mathrm{~mm}$.

Miniestacas extraídas de plantas matrizes, de três clones, de duas espécies florestais, em casa de vegetação/viveiro, foram coletadas durante o período de março a abril e submetidas a diferentes tratamentos para avaliar o potencial de indução do enraizamento.

Realizou-se dois experimentos em esquema fatorial de $3 \times 2$, com cinco tratamentos cada: 1) Três clones $\left(C_{1}, C_{2}\right.$ e $\left.C_{3}\right)$ de $T$. ciliata da linha BV1000 (primeira geração de clones desenvolvidos e registrados pela empresa, oriundos da seleção em um teste de procedências e progênies); 2) Três clones $\left(\mathrm{E}_{1}, \mathrm{E}_{2}\right.$ e $\left.\mathrm{E}_{3}\right)$ de híbridos de $E$. grandis $\mathrm{x}$. urophylla. Para ambos os 
experimentos, os três clones foram combinados com duas condições de preparo das miniestacas (com e sem a redução de $50 \%$ do limbo foliar, Figura 1).

Cada unidade experimental (ou parcela) foi constituída de 11 miniestacas $(6-8 \mathrm{~cm}$ de comprimento), num delineamento inteiramente casualizado, com três repetições. As estacas foram dispostas em tubetes $\left(55 \mathrm{~cm}^{3}\right)$, esterilizados, contendo substrato comercial (Bioplant ${ }^{\circledR}$ ) e fixados em bandejas plásticas, numa densidade de 748 miniestacas por $\mathrm{m}^{2}$.

No preparo das estacas, para a espécie $T$. ciliata, que possui folhas compostas, a redução de $50 \%$ do limbo foliar foi entendida como a divisão da raque em metade do seu comprimento total. Durante o preparo das miniestacas foi avaliado o tempo médio, medido em minutos gastos com o preparo total de 77 miniestacas por tratamento, para o rendimento operacional da atividade.

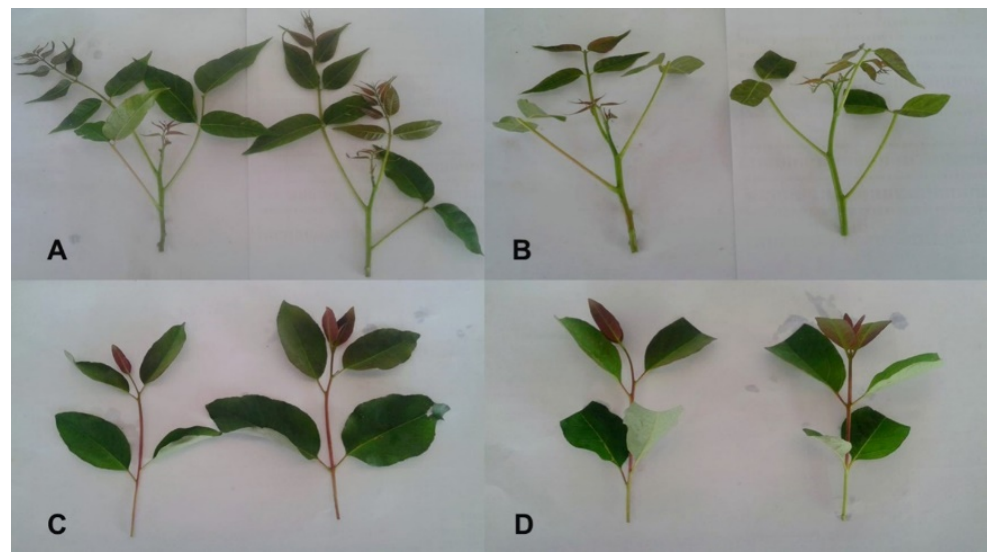

Figura 1. Preparo das estacas de Toona ciliata e Eucalyptus grandis $x$ Eucalyptus urophylla, (A) Toona ciliata com folhas inteiras, (B) Toona ciliata com 50\% de redução foliar, (C) Eucalyptus grandis x Eucalyptus urophylla com folhas inteiras e (D) Eucalyptus grandis x Eucalyptus urophylla com $50 \%$ de redução foliar.

Para manter a viabilidade do material vegetativo, as miniestacas foram acondicionadas em caixas de isopor e pulverizadas com água até a etapa de estaqueamento. As miniestacas foram acondicionadas em casa de vegetação climatizada, com controle automático da aspersão e controle manual das janelas zenitais com o propósito de manter a oscilação de temperatura em torno dos $29^{\circ} \mathrm{C}$ e umidade relativa do ar acima de $90 \%$.

Dados de porcentagem de miniestacas com indução inicial ou algum grau de modificação (PMM\%), caracterizada pelo intumescimento da base da miniestaca e ou formação de calos e ou presença de primórdios radiculares com o comprimento igual ou inferior a $2 \mathrm{~mm}$, porcentagem de enraizamento(PME\%)e a porcentagem de raízes com $\geq 10 \mathrm{~cm}$ (PMR10\%),foram coletados a cada quatro dias até 28 dias. No $28^{\circ}$ dia após o estaqueamento, foi quantificada a massa seca das raízes. As raízes foram lavadas e secas em estufa, a $105^{\circ} \mathrm{C}$ por 72 horas, com posterior pesagem em balança digital com precisão de 0,01 g.

Dados originais de cada parâmetro foram submetidos à análise de variância (ANOVA) e quando detectadas significâncias pelo teste $F$, as médias foram comparadas pelo teste de Tukey, ao nível de 5\% de probabilidade de erro, por meio do software SISVAR (Ferreira, 2011).

A porcentagem de miniestacas com indução inicial foi utilizada para o ajuste da função racional: $\quad Y=(a+b T) /\left(1+c T+d T^{2}\right)$, em que: $\mathrm{Y}=$ percentual de miniestacas modificadas $\mathrm{e}$ $\mathrm{T}=$ número de dias após o estaqueamento. A porcentagem de miniestacas enraizadas e a porcentagem de miniestacas com raízes $\geq 10 \mathrm{~cm}$ foram utilizadas para o ajuste da função logística: $Y=a\left(1+\beta e^{-y \tau}\right)^{-L}$, em que: $Y=$ percentual de miniestacas enraizadas ou percentual de miniestacas com raízes $\geq 10 \mathrm{~cm}$, e $\mathrm{T}$ = número de dias após o estaqueamento, de acordo com a metodologia descrita por Melo et al. (2011). As equações obtidas, pelo software Curve Expert 1.4, em cada clone, foram comparadas, utilizando o procedimento estatístico proposto por Leite \& Oliveira (2002), a 5\% de probabilidade de erro.

\section{RESULTADOS}

O tempo médio entre a coleta, o preparo e o estaqueamento para os três clones foi de3,18e 1,74min, com o uso de folhas inteiras, diferindo (Tukey; $p=0,05$ ), significativamente 
quando comparados com a redução foliar em $50 \%$ e,5,53min e 3,11 min para $T$. ciliatae E. grandis $\times$ E. urophylla, respectivamente (Tabela 1). Os ganhos de eficiência atingidos pela eliminação da etapa de redução do limbo foliar são da ordem de $43 \%$ para $T$. ciliatae de $44 \%$ para $E$. grandis $\times$ E. urophylla. (Tabela 1).

Tabela 1. Tempo médio (minutos) do processo de coleta e preparo de 77 miniestacas de três clones( $\mathrm{C} 1$, C2 e C3) de Toona ciliata e três clones (E1, E2 e E3) de Eucalyptus grandis x Eucalyptus urophylla, sob diferentes métodos de preparo (T1 e T2).

\begin{tabular}{|c|c|c|c|c|c|c|}
\hline \multirow[b]{2}{*}{ Forma de preparo } & \multicolumn{3}{|c|}{ Toona ciliata } & \multicolumn{3}{|c|}{ E. grandis $x$ E. urophylla } \\
\hline & Clone & $\begin{array}{c}\text { Tempo } \\
\text { (min) }\end{array}$ & $\begin{array}{l}\text { Média } \\
\text { (min) }\end{array}$ & Clone & $\begin{array}{c}\text { Tempo } \\
\text { (min) }\end{array}$ & $\begin{array}{l}\text { Média } \\
\text { (min) }\end{array}$ \\
\hline $\mathrm{T1}$ & $\mathrm{C} 1$ & $5,45 B$ & & E1 & $3,15 B$ & \\
\hline \multirow[t]{2}{*}{$\begin{array}{l}\text { (50\% de redução } \\
\text { foliar) }\end{array}$} & $\mathrm{C} 2$ & $5,56 \mathrm{~B}$ & $5,53 \mathrm{~B}$ & E2 & $3,02 \mathrm{~B}$ & $3,11 \mathrm{~B}$ \\
\hline & $\mathrm{C} 3$ & $5,58 \mathrm{~B}$ & & E3 & $3,17 \mathrm{~B}$ & \\
\hline T2 & $\mathrm{C} 1$ & $3,19 \mathrm{~A}$ & & E1 & $1,45 \mathrm{~A}$ & \\
\hline \multirow[t]{2}{*}{ (com folhas inteiras) } & $\mathrm{C} 2$ & $3,21 \mathrm{~A}$ & $3,18 \mathrm{~A}$ & E2 & $2,35 \mathrm{AB}$ & $1,74 \mathrm{~A}$ \\
\hline & $\mathrm{C3}$ & $3,15 \mathrm{~A}$ & & E3 & $1,43 \mathrm{~A}$ & \\
\hline Redução Relativa (\%) & & & $43 \%$ & & & $44 \%$ \\
\hline
\end{tabular}

Médias seguidas pela mesma letra, na coluna, não diferem estatisticamente, a 5\% de probabilidade de erro, pelo teste Tukey.

Os dois modelos de estimativas foram os que apresentaram as melhores distribuições dos dados para as três características avaliadas (função racional para porcentagem de miniestaca com indução inicial e função logística para as características porcentagem de miniestacas enraizadas e para porcentagem de miniestacas com raízes $\geq 10 \mathrm{~cm}$ ) (Figuras 2 e 3).
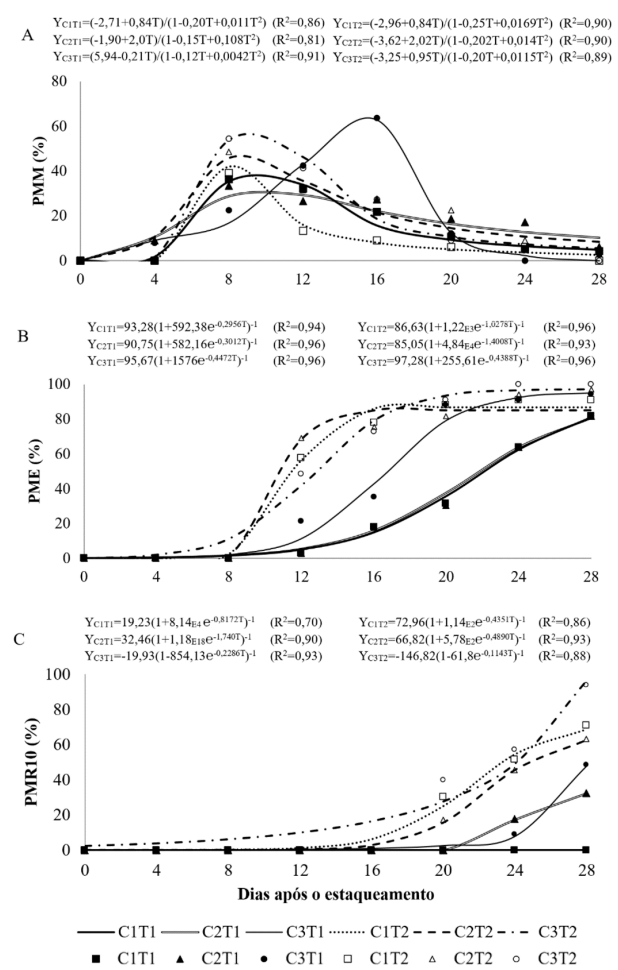

Figura 2. Evolução da porcentagem de miniestacas com: (A)indução inicial; (B) Enraizadas e; (C)com raízes $\geq 10 \mathrm{~cm}$, em função do tempo após o estaqueamento para os três clones (C1, C2 e C3) de Toona ciliata e a forma de preparo (T1- com redução foliar de 50\%, e T2-com folhas inteiras). 


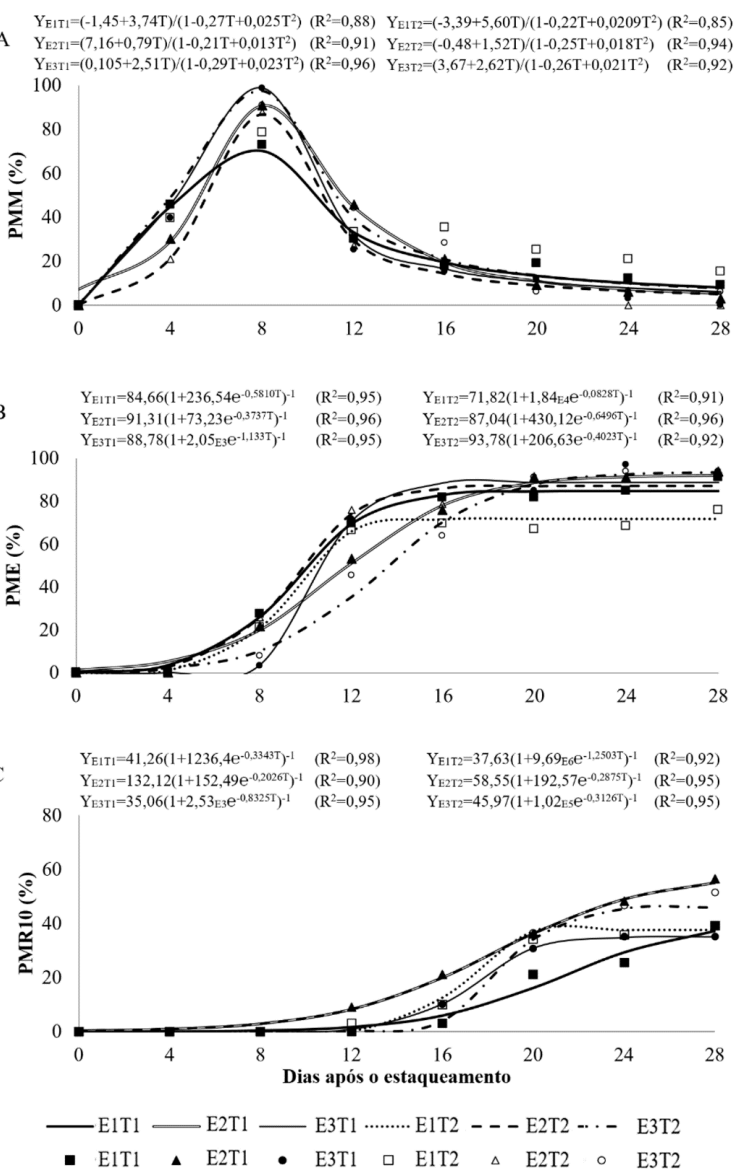

Figura 3. Evolução da porcentagem de miniestacas com: (A) indução inicial; (B) Enraizadas e; (C) com raízes $\geq 10 \mathrm{~cm}$, em função do tempo após o estaqueamento para os três clones (E1, E2 e E3) de Eucalyptus grandis x Eucalyptus urophylla e a forma de preparo (T1- com redução foliar de 50\%, e T2com folhas inteiras).

A maior porcentagem de miniestacas com indução inicial (PMM\%) em T. ciliata ocorreu com as miniestacas com folhas inteiras (T2) (Figura 2A). Os dois tratamentos avaliados obtiveram um padrão de pico de diferenciação do tecido próximo ao $8^{\circ}$ dia após 0 estaqueamento. O clone C3 com redução foliar de 50\% comportou-se de maneira diferencial, obtendo um pico de diferenciação tardio, próximo ao $16^{\circ}$ dia após o estaqueamento.

A maior e significativa porcentagem de miniestacas enraizadas em T. ciliata (PME\%) foi observada quando mantidas as folhas inteiras (T2) (Figura 2B).Estas seguiram um padrão de crescente porcentagem de enraizamento, iniciando no $12^{\circ}$ dia e alcançando o máximo entre - $16^{\circ}$ e o $20^{\circ}$ dia após o estaqueamento. Para os tratamentos com redução foliar de $50 \%$, apenas um clone (C3) estabilizou o percentual de enraizamento antes do $28^{\circ}$ dia após o estaqueamento.

As miniestacas de $T$. ciliata conduzidas com folhas inteiras (T2) apresentaram maiores e significativas porcentagens de raízes $\geq 10 \mathrm{~cm}$ (2C). O clone C1 com redução foliar de $50 \%$ foi o único tratamento a não apresentar nenhuma miniestaca com raízes aparentes ao fundo do recipiente, em contrapartida o mesmo clone C1 com miniestacas conduzidas com folhas inteiras apresentou mais de $60 \%$ das miniestacas com raízes $\geq 10 \mathrm{~cm}$.

Diferentemente dos resultados de $T$. ciliata, os clones de $E$. grandis $\times$ E. urophylla apresentaram comportamentos similares em ambas as formas de preparo das miniestacas para as curvas de miniestacas com indução inicial (Figura 3A), de enraizamento (Figura 3B) e de raízes $\geq 10 \mathrm{~cm}$ (Figura $3 C$ ).

A porcentagem de miniestacas com indução inicial (PMM\%) apresenta, semelhante à T. ciliata, um pico de diferenciação dos tecidos próximo do $8^{\circ}$ dia após o estaqueamento 
(Figura 3A). Contudo, nos clones de E. grandis x E. urophylla existe uma maior magnitude na porcentagem de miniestacas com indução inicial, sendo esses entre 60 e 100\%. Não se observa comportamentos discrepantes entre o método de preparo das miniestacas e nem entre os clones.

O enraizamento das miniestacas em clones de E. grandis x E. urophylla inicia próximo ao $12^{\circ}$ dia após o estaqueamento, sendo alcançado um patamar para todos os tratamentos próximo ao $20^{\circ}$ dia (Figura 3B). O percentual de miniestacas com raízes $\geq 10 \mathrm{~cm}$ apresenta um pico próximo ao $20^{\circ}$ dia após o estaqueamento, alcançando os maiores valores, de 40 a $60 \%$, no $28^{\circ}$ dia (Figura 3C).

Com relação à média do acúmulo de massa seca nas raízes no $28^{\circ}$ dia após o estaqueamento, as duas espécies apresentaram comportamentos distintos uma da outra em função dos métodos de preparo das miniestacas. Com a manutenção das folhas inteiras houve um aumento relativo de $115 \%$ da massa seca de raízes para $T$. ciliatae de 33\% para E. grandis x E. urophylla. (Tabela 2), em comparação ao método de redução foliar em $50 \%$. A espécie $T$. ciliata apresentou uma interação significativa entre os clones e os métodos de preparo da miniestaca para o acúmulo de massa seca. Os clones de T. ciliata não se diferiram entre si quando houve redução de $50 \%$ da área foliar (T1), porém, quando as miniestacas foram conduzidas com folhas inteiras (T2), o clone C1 apresentou maior massa radicular que os demais clones. Quando se compara os tratamentos entre os clones, observa-se que todos os clones produzidos em miniestacas com folhas inteiras (T2) apresentaram massa seca radicular maior que os produzidos com a redução do limbo foliar (T1).

Para os híbridos de E. grandisx E. urophylla não houve interação significativa entre os clones e os métodos de preparo da miniestaca (Tabela 2). Quanto ao método de preparo das miniestacas, as mudas conduzidas com as folhas inteiras (T2) produziram, em média, os maiores valores de massa seca radicular. Quanto aos clones, houve uma maior produção de massa seca radicular no E1 (2,48 g) e E3 (2,65 g) e um menor acúmulo no E2 (1,94 g).

Tabela 2. Massa seca radicular (MSR), em gramas, de clones das espécies Toona ciliata e Eucalyptus grandis x Eucalyptus urophylla, sob diferentes métodos de preparo de miniestacas, ao $28^{\circ}$ dia após o estaqueamento.

\begin{tabular}{|c|c|c|c|c|c|c|}
\hline \multirow{2}{*}{ Forma de preparo } & \multicolumn{3}{|c|}{ Toona ciliata } & \multicolumn{3}{|c|}{ E. grandis $x$ E. urophylla } \\
\hline & Clone & MSR (g) & Média & Clone & MSR (g) & Média \\
\hline & C1 & $2,56 a$ & & E1 & $2,22 \mathrm{a}$ & \\
\hline \multirow[t]{3}{*}{ T1 (50\% de redução foliar) } & $\mathrm{C} 2$ & $2,54 \mathrm{a}$ & $2,51 \mathrm{~B}$ & E2 & $1,54 \mathrm{a}$ & $2,02 \mathrm{~B}$ \\
\hline & $\mathrm{C} 3$ & $2,44 a$ & & E3 & $2,31 \mathrm{a}$ & \\
\hline & $\mathrm{C} 1$ & $6,86 \mathrm{a}$ & & E1 & $2,75 \mathrm{a}$ & \\
\hline \multirow[t]{2}{*}{ T2 (com folhas inteiras) } & $\mathrm{C} 2$ & $4,73 \mathrm{~b}$ & $5,41 \mathrm{~A}$ & E2 & $2,35 \mathrm{a}$ & $2,70 \mathrm{~A}$ \\
\hline & $\mathrm{C} 3$ & $4,63 \mathrm{~b}$ & & E3 & $3,01 \mathrm{a}$ & \\
\hline Aumento Relativo & & & $115 \%$ & & & $33 \%$ \\
\hline
\end{tabular}

Médias seguidas pela mesma letra maiúscula, na coluna, e minúscula, dentro do mesmo método de preparo das miniestacas, não diferem estatisticamente, a 5\% de probabilidade de erro pelo teste Tukey.

\section{DISCUSSÃO}

No presente estudo, observou-se que o tempo de preparo das miniestacas foi menor quando as folhas permaneceram inteiras, garantido uma otimização das etapas de produção, além de resultar nas maiores médias em massa seca radicular das miniestacas nas duas espécies testadas. A condução das miniestacas com folhas inteiras proporciona um aumento do acúmulo de carboidratos oriundo do processo fotossintético, favorecendo o enraizamento mais acelerado quando comparado à redução do limbo foliar (Hartmann et al., 2011).

A redução de $50 \%$ do limbo foliar é o procedimento padrão adotado pela maioria das empresas florestais e em estudos científicos. Possui como justificativa garantir uma menor perda de água pela transpiração foliar, além de facilitar a água da irrigação chegar ao 
substrato, evitando o efeito "guarda-chuva" (Alfenas et al., 2009). No entanto, não foi observado a deficiência da irrigação nos substratos quando as folhas foram mantidas inteiras.

A eliminação da etapa de redução foliar no preparo das miniestacas reduz $44 \%$ do tempo necessário para a coleta, o preparo e o estaqueamento, tornando a operação mais eficiente (Tabela 1). O maior ganho operacional, a redução de mão de obra, o aumento de produtividade no preparo das miniestacas e a diminuição dos riscos de lesões operacionais e de lesões por esforço repetitivo aos trabalhado respodem ser citados como alguns dos benefícios pela eliminação da etapa de redução foliar no preparo de miniestacas (Maciel et al., 2012; Mayer et al., 2018).

De acordo com Correia et al. (2015), o emprego de miniestacas de Eucalyptus globulus com folhas inteiras apresenta uma serie de pontos positivos para a produção de mudas, como no enraizamento, no controle de doenças e mais notavelmente na velocidade de enraizamento, no número de raízes e na biomassa radicular. No presente estudo, esse fenômeno foi observado na espécie $T$. ciliata, cuja condução das miniestacas com folhas inteiras promoveu um enraizamento mais rápido (Figura 2). Para os clones de E. grandisx $E$. urophylla utilizados, não houve diferença quanto à velocidade de enraizamento nas miniestacas em relação à forma de preparo, sendo recomendado manter as folhas inteiras das miniestacas, uma vez que possui benefícios quanto à eficiência da operação e ganhos na massa seca radicular das mudas (Tabelas 1 e 2).

Com relação à média do acúmulo de massa seca nas raízes no $28^{\circ}$ dia após o estaqueamento, a T. ciliata apresentou uma interação significativa entre os clones e os métodos de preparo da miniestaca, ou seja, há diferentes respostas entre os clones e os métodos de preparo da miniestaca (Tabela 2).

Há poucos estudos referentes à propagação vegetativa de $T$. ciliatapor miniestaquia. Souza et al. (2009) ressaltaram o sucesso da técnica de propagação vegetativa da T. ciliata pela miniestaquia sem a necessidade da aplicação de auxina, padronizando miniestacas apicais com tamanho de 4 a $6 \mathrm{~cm}$ e duas folhas reduzidas pela metade. Ferreira et al. (2012), mantendo duas folhas reduzidas à metade, obtiveram enraizamento acima de 95\% para miniestacas de $T$. ciliata.

Este é o primeiro trabalho testando a necessidade ou não de redução do limbo foliar. No presente estudo, a condução de miniestacas de $T$. ciliata com folhas inteiras resultou no enraizamento mais rápido e no maior acúmulo de massa seca radicular quando comparado com miniestacas conduzidas com folhas reduzidas pela metade.

Já, para as espécies do gênero Eucalyptus, são encontrados vários estudos na literatura com a condução de miniestacas com folhas inteiras, indicando resultados positivos na produção de mudas de Eucalyptus benthamii (Mayer et al., 2018), híbridos de E. grandis $x$ E. urophylla (Moraes et al., 2014a; Souza et al., 2013), híbridos de E.urophylla x E. globulus e E. grandis x E. globulus (Correia et al., 2015) e híbridos de E. urophylla (Santana et al., 2010). No presente estudo, as miniestacas de E. grandis $\times$ E. urophylla conduzidas com folhas inteiras proporcionaram um aumento de $33 \%$ de massa seca radicular quando comparadas às miniestacas conduzidas com redução foliar de $50 \%$.

\section{CONCLUSÃO}

A condução de miniestacas com folhas inteiras promoveu uma redução do tempo de preparo das miniestacas, tanto para os clones de Toona ciliata, quanto para os clones de Eucalyptus grandis x Eucalyptus urophylla.

O preparo das miniestacas de Toona ciliata com a manutenção das folhas inteiras resultou no enraizamento mais rápido e no maior acúmulo de massa seca radicular.

Para os clones de Eucalyptus grandis x Eucalyptus urophylla, a condução de miniestacas com folhas inteiras não influenciou na velocidade do enraizamento, mas resultou no maior acúmulo de massa seca radicular. 


\section{REFERÊNCIAS}

Alfenas, A. C., Zauza, A. A. V., Mafia, R. G., \& Assis, T. F. (2009). Clonagem e doenças do eucalipto (2. ed., 500 p.). Viçosa, MG: Universidade Federal de Viçosa.

Correia, A. C. G., Xavier, A., Dias, P. C., Titon, M., \& Santana, R. C. (2015). Redução foliar em miniestacas e microestacas de clones híbridos de Eucalyptus globulus. Revista Árvore, 39(2), 295-304. http://dx.doi.org/10.1590/0100-67622015000200009.

Dantas, A. A. A., Carvalho, L. G., \& Ferreira, E. (2007). Classificação e tendências climáticas em Lavras, MG. Ciência e Agrotecnologia, 31(6), 1862-1866. http://dx.doi.org/10.1590/S141370542007000600039.

Ferreira, D. A., Barroso, D. G., Silva, M. P. S., Souza, J. S., Freitas, T. A. S., \& Carneiro, J. G. A. (2012). Influência da posição das miniestacas na qualidade de mudas de cedro australiano e no seu desempenho inicial no pós-plantio. Ciência Florestal, 22(4), 715-723. http://dx.doi.org/10.5902/198050987553.

Ferreira, D. F. (2011). Sisvar: a computer statistical analysis system. Ciência e Agrotecnologia, 35(6), 10391042. http://dx.doi.org/10.1590/S1413-70542011000600001.

Goulart, P. B., \& Xavier, A. (2010). Influência do modo de acondicionamento de miniestacas no enraizamento de clones de Eucalyptus grandis x E. urophylla. Revista Árvore, 34(3), 407-415. http://dx.doi.org/10.1590/S0100-67622010000300004.

Hartmann, H. T., Kester, D. E., Davies Junior, F. T., \& Geneve, R. L. (2011). Plant propagation: principles and practices (8. ed.). New Jersey: Prentice Hall.

Leite, H. G., \& Oliveira, F. H. T. (2002). Statistical method to test the identity of analytical methods. Communications in Soil Science and Plant Analysis, 6(1), 22.

Lorenzi, H. (2003). Árvores exóticas no Brasil: madeireiras, ornamentais e aromáticas. Nova Odessa: Institituto Plantarum de Estudos da Flora.

Maciel, C. M., Brasileiro, M., \& Freitas, C. (2012). Avaliação ergonômica das atividades de produção de mudas em viveiro florestal de Vitória da Conquista - Ba. Enciclopédia Biosfera, 8, 1-4.

Mayer, E. L. P., Peres, F. B., \& Tambarussi, E. V. (2018). Arquitetura foliar de miniestacas e aplicação de biofertilizante à base de aminoácidos na miniestaquia de Eucalyptus benthamii Maiden \& Cambage. Scientia Forestalis, 46(118), 251-260. http://dx.doi.org/10.18671/scifor.v46n118.11.

Melo, L. A., Xavier, A., Paiva, H. N., \& Borges, S. R. (2011). Otimização do tempo necessário para o enraizamento de miniestacas de clones híbridos deEucalyptus grandis. Revista Árvore, 35(4), 759-767. http://dx.doi.org/10.1590/S0100-67622011000500001.

Moraes, C. E., Fonseca, R. C. M., \& Rui, M. (2014a). Influence of leaves in rooting of minicuttings of Eucalyptus hybrids. Nucleus, 11(1), 101-106. http://dx.doi.org/10.3738/1982.2278.995.

Moraes, D. G., Barroso, D. G., Figueredo, F. A. M. M. A., Silva, T. R. C., \& Freitas, T. A. S. (2014b). Enraizamento de miniestacas caulinares e foliares juvenis de Toona ciliata M. Roemer. Magistra, 26(1), 47-54.

Moretti, B. S., Furtini Neto, A. E., Pinto, S. I. C., Furtini, I. V., \& Magalhães, C. A. S. (2011). Crescimento e nutrição mineral de cedro australino (Toona ciliata) sob omissão de nutrientes. Cerne, 17(4), 453463. http://dx.doi.org/10.1590/S0104-77602011000400003.

Nassur, O. A., Rosado, L. R., Rosado, S. C. S., \& Carvalho, P. M. (2013). Qualidade de toras de Toona ciliata M. Roemer. com dezoito anos de idade. Cerne, 19(1), 43-49. http://dx.doi.org/10.1590/S010477602013000100006.

Oliveira, L. S., Xavier, A., Dias, P. C., Correia, A. C. G., Borges, S. R., Takahashi, E. K., \& Paiva, H. N. (2012). Enraizamento de miniestacas e microestacas de clones de Eucalyptus urophylla $\times$ E. globulus e de Eucalyptus grandis x E. globulus. Scientia Forestalis, 40(96), 507-516.

Pacheco, J. M., Figueiro Filho, A., Dias, A. N., Machado, A., \& Lima, R. (2015). Efeito da densidade inicial no crescimento de Pinus taeda L. na região Centro Sul do Paraná. Scientia Forestalis, 43(106), $353-$ 365.

Pereira, M. O., Wendling, I., Nogueira, A. C., Kalil Filho, A. N., \& Navroski, M. C. (2015). Resgate vegetativo e propagação de cedro-australiano por estaquia. Pesquisa Agropecuária Brasileira, 50(4), 282-289. http://dx.doi.org/10.1590/S0100-204X2015000400003.

Ribeiro, A. O., Mendes, R. F., Mendes, L. M., Mori, F. A., \& Ziech, R. Q. S. (2014). Retratibilidade da madeira de Toona ciliataM. Roemer proveniente de três municípios do sul de Minas Gerais. Cerne, 20(3), 351-361. http://dx.doi.org/10.1590/01047760201420031315. 
Santana, R. C., Dutra, T. R., Carvalho Neto, J. P., Nogueira, G. S., Grazziotti, P. H., \& Barros Filho, N. F. (2010). Influenceof leaf area reduction on clonal production of Eucalyptus seedlings. Cerne, 16(3), 251-257. http://dx.doi.org/10.1590/S0104-77602010000300001.

Souza, C. C., Xavier, A., Leite, F. P., Santana, R. C., \& Leite, H. G. (2013). Padrões de miniestacas e sazonalidade na produção de mudas clonais de Eucalyptus grandis Hill X E. urophylla S. T. Black. Revista Árvore, 37(1), 67-77. http://dx.doi.org/10.1590/S0100-67622013000100008.

Souza, J. C. A. V., Barroso, D. G., \& Carneiro, J. G. A. (2010). Cedro australiano (Toona ciliata). Niterói: Rio Rural.

Souza, J. C. A. V., Barroso, D. G., Carneiro, J. G. A., Teixeira, S. L., \& Balbinot, E. (2009). Propagaçãovegetativa de cedro-australiano (Toona ciliata M. Roemer) por miniestaquia. Revista Árvore, 33(2), 205-213. http://dx.doi.org/10.1590/S0100-67622009000200002.

Xavier, A., \& Silva, R. L. (2010). Evolução da silvicultura clonal de Eucalyptus no Brasil. Agronomia Costarricense, 34(1), 93-98.

Contribuição dos Autores: RSA: supervisão, validação, visualização, escrita - original, revisão e edição; DBA: coleta de dados, analise formal, investigação, metodologia, escrita - original; JCTF: analise formal, validação, visualização, escrita - revisão e edição; LAM, ECS e ESV: concepção, supervisão, recursos, administração do projeto. 